\title{
Search engine liability for autocomplete suggestions: personality, privacy and the power of the algorithm
}

\author{
Stavroula Karapapa* and Maurizio Borghi ${ }^{\dagger}$
}

\begin{abstract}
This article is concerned with the liability of search engines for algorithmically produced search suggestions, such as through Google's 'autocomplete' function. Liability in this context may arise when automatically generated associations have an offensive or defamatory meaning, or may even induce infringement of intellectual property rights. The increasing number of cases that have been brought before courts all over the world puts forward questions on the conflict of fundamental freedoms of speech and access to information on the one hand, and personality rights of individualsunder a broader right of informational self-determination - on the other. In the light of the recent judgment of the Court of Justice of the European Union (EU) in Google Spain $v A E P D$, this article concludes that many requests for removal of suggestions including private individuals' information will be successful on the basis of EU data protection law, even absent prejudice to the person concerned.

KEYWORD S : ISP liability; defamation; data protection; trade mark infringement; intellectual property; freedom of speech; false light; right to be forgotten
\end{abstract}

\section{INTRODUCTION}

This article is concerned with the liability of search engines for automatically produced search suggestions. With a number of cases having being brought before courts all over the world, Google Instant Search, also known as the autocomplete suggestion function, has become a paradigmatic instance where freedom of information and personality interests may come in conflict in the online world. ${ }^{1}$

* University of Reading, UK. E-mail: s.karapapa@reading.ac.uk

Bournemouth University, UK. E-mail: mborghi@bournemouth.ac.uk

1 To our knowledge, claims regarding the autocomplete function of search engines appear in over 25 cases that have been brought before courts in more than 10 jurisdictions. Four of these cases have reached the relevant Supreme Court (one in Germany and three in France). Claims have been brought on the basis of both common law torts and statutory rights: defamation, false light, damage to business reputation, negligence, inducement to copyright infringement, trade mark infringement, breach of privacy and data protection law. Many cases have been settled before reaching a judgment.

(C) The Author (2015). Published by Oxford University Press. All rights reserved. For Permissions, please email: journals.permissions@oup.com. 
This technical feature, which is now commonly provided by all search modules, ${ }^{2}$ means to speed up the process of entering a query by 'suggesting' the word(s) that a user would type before the user actually finishes entering the query in the search bar. Through these 'suggestions', words may be automatically completed or associated with other words based on a complex algorithm. The main factors that influence the algorithm are the popularity of searches made by Internet users and of the web pages indexed by the search engine, even though other objective factors are also taken into account, such as the user's geographical location and their prior search history. ${ }^{3}$

Legal problems arise when the algorithm generates a combination of words that is capable of conveying a deceitful or misleading message. For instance, a person's or a business's name may be associated with terms suggesting dishonest activities, such as 'fraud' or 'scam', ${ }^{4}$ or revealing unwanted details on one's person past. ${ }^{5}$ In some instances, the association may not just be frustrating or embarrassing for the person or business, but purely groundless, mistaken or false. ${ }^{6}$ On a different matter, by effect of the popularity of search queries, the title of a song or of a film may be regularly associated with terms like 'torrent' or 'megaupload', thereby directing users' surfing towards the troubled waters of online piracy. ${ }^{7}$ In the same vein, trademarks may

2 Not only by 'general' search engines like Google, Bing or Yahoo!, but also by 'vertical' search engines as those implemented, for instance, on eBay and Amazon (see Cosmetic Warriors Ltd v Amazon.co.uk Ltd [2014] EWHC 181 (Ch), discussed below, Section 8).

3 Google search engine employs three related features: Google Instant, Autocomplete (also known as Google Suggest), and Related Searches. As soon as a user starts typing a term in the search box: (i) Google Instant predicts what the user is looking for and shows results; (ii) autocomplete displays a menu of 'search predictions'; and (iii) searches related to the term (Related Searches) appear near the bottom of the page. Users can report 'offensive predictions' made by Autocomplete <https://support.google.com/ websearch/answer/106230?hl=en > accessed 20 May 2015.

4 Google/Lyonnaise de garantie, Cour de Cassation, 19 June 2013 (France) (name of a company associated with 'escroc' [fraud]); Direct Energie/Google, Tribunal de Commerce de Paris, Ord 7 May 2009 (France) (name of a company associated with 'arnaque' [scam]); Albert Tanneur Institut \& Co c. Google Inc, Tribunal Cantonal du Jura, 12 February 2011 (Switzerland) (name of a person and company associated with 'scam'); OLG Hamburg, 3 U 67/11, 26 May 2011 (Germany) (name of a company associated with 'fraud' [Betrug] and 'conspiracies' [Machenschaften]); OLG Munich, 29 U 1747/11, 29 September 2011 (Germany) (name of a company association with 'abzocke' [rip-off]); X c. Google Tribunale Ordinario di Milano, N RG 2012/68306, 25 March 2013 (Italy) (person's name associated with 'setta' [sect], 'plagio' [brainwashing] and 'truffa' $[$ scam]).

5 Mme C/Google France, TGI Montpellier, 28 October 2010; affd in CA Montpellier Ch 5, s A, 29 September 2011 (France) (plaintiff's name associated with title of adult movie); Pierre B. /Google Inc, Cour de Cassation, 19 February 2013 (France) (name associated with words 'viol' [rape], 'condamné' [sentenced]); LG Mönchengladbach, 10 O 170/12, 5 September 2013 (Germany) (plaintiff's name associated with 'Stasi', the secret police of former East Germany); Rechtbank Amsterdam, 19 October 2014 (Netherlands) (association with name of well-known crime journalist who covered the event where the plaintiff was involved).

6 Guy Hingston v Google Inc, US District Court, SACV 12 - 02202 JST (name of a person associated with 'bankruptcy'); LG Munich, 17 June 2013 (TV-Wartezimmer GmBH) (Germany) (name of a company associated with 'Insolvenz' [insolvency]); OLG Köln, 15 U 199/11, 10 May 2012 (Germany) (person's name associated with 'Scientology'); X c. Google, Tribunale Ordinario di Pinerolo (Italy), 23 March 2012 (name associated with 'indagato' [under investigation] and 'arrestato' [under arrest]).

7 Syndicat National de l'Édition Phonographique (SNEP)/Google, Cour de Cassation, 12 July 2012 (France). 
appear in the search bar as effect of word associations in a way that allegedly causes confusion. ${ }^{8}$

Whereas many cases of this nature have been judicially examined all over the world, the outcomes have been diverse and legal uncertainty remains. ${ }^{9}$ In some instances, the search engine was found liable for defamation upon receiving notification of allegedly offensive content, and in other cases it did not. Based on comparable assumptions, courts have upheld claims for inducement of copyright infringement and dismissed allegations of damage to reputation. The search engine's freedom of speech and freedom to conduct business has been variously balanced against users' personality and business interests. Similarly, the safe harbour provisions for Internet intermediary activities have been inconsistently weighted against the possibly active role of the search engine as publisher, as content provider or as data controller.

Besides the fact that courts may reach different conclusions as to the liability of the search engine, the logic they follow in reaching a judicial outcome varies substantially to an extent that no solid judicial trend can be assumed. This is not only because laws protecting personality and corporate rights differ from jurisdiction to jurisdiction, and there are also variations on a case-by-case basis, but also because of the ambiguity as to whether algorithmically determined word combinations can actually bear a connotative meaning that could thereinafter result in legal implications. With the lack of a settled legal contour on how to determine whether automated associations in the context of online searches can determine liability, the questions inevitably arise: can search suggestions have a meaning that could be offensive, defamatory, prejudicial to business reputation, or that can it even induce illicit behaviours, such as copyright or trademark infringement? If this is the case, what are the obligations of the operators of search engines for the suggestions generated by their algorithms? And what is, and should be, the extent of their responsibility?

In this article, we discuss the relevant rulings to argue that search engine liability for autocomplete suggestions can better be understood on the background of another, more fundamental question, namely: what is the legal nature of 'search queries' and who owns the data generated by the collective effect that these queries may produce? Based on the judgment of the Court of Justice of the European Union (CJEU) in Google Spain $v$ AEPD, ${ }^{10}$ we conclude that many requests for removal of suggestions including private individuals' information will be successful on the basis of EU data protection law, even absent prejudice to the person concerned. However, no general obligation can be assumed for suggestions related to companies or public persons' names, or otherwise colliding with property or image rights.

8 OLG Braunschweig, 2 U 8.12, 2 March 2014 (Poster Lounge) (Germany). See also Cosmetic Warriors Ltd v Amazon.co.uk Ltd [2014] EWHC 181 (Ch) (UK) (trade mark associated with names of competing products in Amazon's scroll-down menu).

9 See $\mathrm{n} 1$.

10 Google Spain SL v Agencia Española de Protección de Datos (AEPD), Case C-131/12, 13 May 2014. 


\section{FACILITATING THE SEARCH: PREDICTING SEARCHES OR ORIENTING THE USERS?}

The autocomplete or word completion feature was reportedly initially designed to assist people with physical disabilities to increase the typing speed. ${ }^{11}$ It was then increasingly applied in search engines and other software-databases, web browsers, email programs, word processors - to facilitate typing the 'right' word(s) when submitting a search query, or entering an email address, or texting a message. Today, there is practically no interactive software applied to computers or smart devices that does not incorporate an autocomplete function as default.

Despite slight variations in the way that the algorithm works, the auto-suggestive keyword services share the purpose of making search easier and faster. How is this 'facilitation' of searches to be understood? The automatically generated suggestions are referred to in some instances as 'predictions, ${ }^{12}$ or elsewhere as ideas and suggestions through which users will 'stop guessing. ${ }^{13}$ It is an open question, however, whether the algorithmically produced suggestions 'predict' what the users would have in any case searched for, or whether they draw the users' attention to searches they would have not otherwise thought of. The everyday experience with search engines indicates that suggestions may have both functions: when one types a word, the appearing list of word combinations normally includes an assortment of pertinent and irrelevant searches, sometimes with the addition of searches that, although not matching the initial intent of the user, indulge one's curiosity and evoke new search patterns. In this last case, 'facilitation' takes the meaning of 'orienting', rather than just speeding up, the search. It is mainly in this scenario that search suggestions become legally relevant.

The ambiguity as to the nature and effect of search suggestions has in fact received wide judicial scrutiny. In a case brought before the Tribunal de Grand Instance of Paris and eventually decided by the Supreme Court, ${ }^{14}$ for example, it was found that a suggested search indulges users' curiosity and orients them towards searches that may hence influence in turn the algorithm. Such a 'snowball effect' goes against the 'neutral algorithm' argument that was set forward by Google in its defence. Far from reflecting neutrally users' preferences, Instant Search can direct users' attention to other searches: by attracting user curiosity, it could orient them towards searches they would have not otherwise performed. ${ }^{15}$

'System and method for providing autocomplete query using automatic query transform' US Patent No $20070050352 \mathrm{~A} 1$.

12 <https://support.google.com/websearch/answer/106230?hl=en> accessed 20 May 2015.

13 <http://www.bing.com/toolbox/keywords> accessed 20 May 2015.

14 M. X./Google Inc., Eric S. et Google France, Tribunal de Grande Instance de Paris, 8 September 2010 (decision reversed by the Court of Appeal, 14 December 2011; the Court of Cassation confirmed the appeal decision on 19 February 2013). The effect has been discussed also in Bruno L., Resources et actualisation/ Google Inc., Google France, TGI Paris, 23 October 2013.

15 This potential 'vicious cycle' has also been discussed by reference to the impact of algorithmic suggestions on US Congressmen. See Kate Turmarello, 'Search Engines are a Thorn on Congress' Side', Roll Call, 5 October 2013 <http://www.rollcall.com/issues/57_78/Google-Searches-Are-a-Thorn-in-Congress-Side211376-1.html > ['If Google autocomplete suggests a certain search term . . . people are more likely to search it; the more people search a certain term, the more likely Google autocomplete is to suggest it'.] accessed 20 May 2015. 
The assumption that the algorithm does not merely 'predict' searches-but could also potentially orient users towards particular searches-is also indirectly demonstrated by the very application of policy filters that ban certain words from being displayed on the search bar as suggestions. In particular, pressure from the entertainment industry and government officials has induced search engines to exclude words such as 'bittorrent', 'torrent' and 'rapidshare' as of $2010 .{ }^{16}$ The word 'megaupload' has also been banned further to a decision of the French Supreme Court in 2012. ${ }^{17}$ More recently, Google has removed the word 'GrooveShark', which is the name of a free streaming company. ${ }^{18}$ By the same token, filters have also been inserted to avoid the completion of words that would amount to hate speech. ${ }^{19}$ This, however, has not stopped the French organization 'SOS Racisme', along with another five organizations to sue Google for hate speech in May 2012. According to the claim, suggestions featured in Google's search bar, such as the words 'Jew' or 'Jewish' after the names of certain public figures, potentially exposing anti-Semitic hate speech. This was allegedly perpetuating stereotypes and advanced racist ideas about Jewish conspiracies. Although it would have been interesting to see what the court would have to say on the matter, the claim was dropped after the parties reached an agreement, about which no further details were given to publicity. ${ }^{20} \mathrm{~A}$ year before the settlement in France, a similar complaint was filed in Argentina by the Jewish organization DAIA, according to which Google was displaying results for 76 sites which DAIA regarded as 'highly discriminatory'. Ordering Google to remove automatic suggestions to these sites in Argentina, the Buenos Aires Court stressed that, although censorship is illegal under Argentine law, there is a constitutional right protecting individuals from discrimination, pointing out that similar decisions had been issued in earlier cases involving printed material. ${ }^{21}$

16 'Google starts censoring Bittorrent, Rapidshare and more', Torrent Freak, 26 January $2011<$ https:// torrentfreak.com/google-starts-censoring-bittorrent-rapidshare-and-more-110126/> accessed 20 May 2015. For a discussion on Google's policy on filtering search results see Danny Friedmann, 'Paradoxes, Google and China: How Censorship can Harm and Intellectual Property can Harness Innovation', in Aurelio Lopez-Tarruella (ed) Google and the Law. Empirical Approaches to Legal Aspects of KnowledgeEconomy Business Models (Springer 2012) 303.

17 Syndicat National de l'Édition Phonographique (SNEP)/Google France, (n 7). See discussion below, Section 8.

18 Jimmy Haas, 'Google’s autosuggest blacklists GrooveShark', zumit, 23 July 2013 < http://zumic.com/ 2013/07/23/googles-autosuggest-blacklists-grooveshark/> accessed 20 May 2015. Similarly, up until recently, Google had blocked the term 'bisexual' from search results generated through the autocomplete function after a campaign by BiNet and other advocacy groups. For a catalogue of words that are blacklisted by Google Instant see 'Google Blacklist-Words That Google Instant Doesn't Like' (2010) 2600 Hacker Quarterly <https://www.2600.com/googleblacklist/> accessed 20 May 2015.

19 <https://support.google.com/websearch/answer/106230?hl=en > accessed 20 May 2015.

20 See Eric Pfanner, 'Racism Lawsuit against Google Dropped', NY Times, 27 June $2012<$ http://www. nytimes.com/2012/06/28/technology/racism-lawsuit-against-google-dropped.html?_r=0 $>$ accessed 20 May 2015.

21 Mariano Castillo and Catherine E Shoichet, 'Argentine Court Blocks Google's “suggested” Searches', CNN, 19 May 2011 <http://edition.cnn.com/2011/TECH/web/05/18/argentina.google/index.html> accessed 20 May 2015. 
Further to the decision of the European Court in Google Spain v AEPD, Google has eventually changed its policy with regards to Autocomplete, allowing users to 'report offensive predictions' by submitting a form. ${ }^{22}$

Where possibly defamatory suggestions are made via the search engine algorithm, the question is whether the search engine should be held liable for these suggestions or not. In this connection, determining liability will largely depend on whether the suggestions generated by the algorithm can be construed as meaningful sentences such as statements of facts or even 'opinions' expressed by the operator of the search engine.

\section{SEARCH SUGGESTIONS AS CONSTITUTIONALLY PROTECTED OPINIONS: FREEDOM OF SPEECH AND THE FIRST AMENDMENT}

The issue is of particular relevance to a jurisdiction like the USA, where opinions may find protection under the constitutional principle of freedom of speech. ${ }^{23}$ In the USA, opinions that result in 'statements on matters of public concern' are protected both when they are about public figures and private individuals, ${ }^{24}$ although in the latter case the constitutional shield is more vulnerable. ${ }^{25}$ As expressed by the Supreme Court in a landmark case which clarified the scope of the so-called 'opinion privilege' under US constitution:

'A statement of opinion relating to matters of public concern which does not contain a provably false factual connotation will receive full constitutional protection. $^{\text {26 }}$

Accordingly, three conditions must be met for an act of speech to receive constitutional protection: (i) there has to be a 'statement of opinion'; (ii) the statement must relate to 'matters of public concern'; and (iii) it must not contain a 'provably false factual connotation'.

To understand search suggestions as a form of speech in the first place, however, one has to consider that US courts have gradually expanded the notion of 'statement of opinion' to include any presentation of information and facts, such as lists of names, stock listings, cooking recipes and computer program source codes. ${ }^{27}$ Along this line, it has been suggested that the US jurisprudence supports the view that algorithm-based decisions-and, in general, outputs of an entirely automated

22 <https://support.google.com/websearch/answer/106230?hl=en> accessed 20 May 2015. See discussion below, Section 7.1.

23 US Const amend I. Also see New York Times Co. $v$ Sullivan (1964) 376 US 254. In Milkovich v Lorain Journal Co. (1990) 497 US 1, 20, the US Supreme Court established that there is no wholesale defamation exemption for opinions.

24 New York Times Co. (n 23).

25 Rosenbloom v Metromedia, Inc. (1971) 403 US 29, 70-71; Gertz v Robert Welch, Inc. (1974) 418 US 323 , 343-46.

26 Milkovich v Lorain Journal Co. (1990) 497 US 1, 20.

27 For a discussion on the definition of 'speech' under the first amendment see Sorrell $v$ IMS Health, Inc. 131. On the issue of search engine liability for defamation in the context of the autocomplete function see Michael L Smith, 'Search Engine Liability for Autocomplete Defamation: Combating the Power of Suggestion’ (2013) 2 J L Tech Pol 313. 
process - are protectable under the First Amendment, as long as the algorithm or the automated process 'communicates' a message to an audience. ${ }^{28}$

In particular, the argument that search results are constitutionally protected speech, has been initially put forward as a defence to accusations of unfair practices, such as exclusion or de-ranking of websites from search results, or anti-competitive behaviour, such as, prioritizing search engine's own thematic search results over results originating from competitors. ${ }^{29}$ In a White Paper commissioned by Google in $2012,{ }^{30}$ Volokh and Falk argue that search engines operate in the same way as media enterprises, which exercise a legitimate editorial judgment 'about what users are likely to find interesting and valuable.' ${ }^{31}$ This such judgment comprises the decision about which information to include and which to exclude from search results, and which are the results to prioritize. In their view, the fact that the choices are implemented through a computerized algorithm does not reduce the protection offered through the First Amendment, as the algorithm itself is written by humans and therefore embodies a human editorial judgment. Even if users may expect that Google presents the results on the basis of supposedly 'neutral' algorithms, 'Google has never given up his right as a speaker to select what information it presents and how it presents it. $^{, 32}$

This approach has been adopted in court decisions too, in relation to claims about the removal or the de-ranking of certain websites in search results, both on allegedly commercial and political grounds. In Search King $v$ Google, the complaint was about purposeful and malicious de-ranking of certain websites in Google search results. ${ }^{33}$ The court upheld Google's argument that its Page Rank system represents speech protected by the First Amendment, and any act aimed at knowingly and intentionally modifying the ranking of websites is legitimate expression of the freedom of speech. ${ }^{34}$ The point was also peripherally made in Langdon $v$ Google, Yahoo! and

Stuart M Benjamin 'Algorithms and Speech' (2013) 161 U Penn L Rev 1445. For an opposite view see Oren Bracha and Frank Pasquale, 'Federal Search Commission? Access, Fairness, and Accountability in the Law of Search' (2008) 93 Cornell L Rev 1149 (arguing that the First Amendment does not preclude regulation of the ability of search engines to manipulate and structure their results).

29 For a discussion of the antitrust controversies around Google, see Sophie von Loon, 'The Power of Google: First Mover Advantage or Abuse of a Dominant Position?' in Aurelio Lopez-Tarruella (ed) Google and the Law. Empirical Approaches to Legal Aspects of Knowledge-Economy Business Models (Springer 2012); Frank Pasquale, The Black Box Society: The Secret Algorithms that Control Money and Information (Harvard UP 2015) 165-68.

30 Eugene Volokh and Donald M Falk, 'First Amendment Protection for Search Engine Search Results', 20 April $2012<$ http://ssrn.com/abstract=2055364 $>$ Accessed 20 may 2015.

31 ibid 5. According to the authors, 'Google, Microsoft's Bing, Yahoo! Search, and other search engine companies are rightly seen as media enterprises, much as the New York Times Company or CNN are media enterprises' 10.

32 ibid 17. See also Josh Blackman, 'What Happens if Data is Speech?' (2014) 16 U Penn J Const L 25.

33 Search King, Inc. v Google Technology, Inc., Inc No 02-1457, 2003 (WD Oklahoma, 27 May 2003). The plaintiff was profiting by selling ad space on websites ranked highly by Google's Page Rank system. Google admitted it intentionally decreased the ranking of the websites at issue because the plaintiffs actions undermined the integrity of the system.

[A] PageRank is an opinion - an opinion of the significance of a particular web site as it corresponds to a search query. Other search engines express different opinions, as each search engine's method of determining relative significance is unique... While Google's decision to 
Microsoft Corp., where one of the complaints was that the defendant search engines had removed the plaintiff's website from search results, thereby acting in a fraudulent, arbitrary and punitive way. ${ }^{35}$ The court dismissed this claim on the ground that the defendants had legitimately exercised an 'editorial decision' and, consequently, had a constitutionally protected right to choose what information to display in search results and what to exclude. ${ }^{36}$ The same conclusion was reached by the New York District Court in Jian Zhang $v$ Baidu. ${ }^{37}$ The plaintiffs in this case were a group of writers and bloggers who were active in the pro-democracy movement in China. They claimed that the search engine Baidu.com was conspiring to prevent their political speech by blocking from its US search results articles and other information concerning the democracy movement in China. In dismissing the claim, the Judge observed that

[t]here is no irony in holding that Baidu's alleged decision to disfavor speech concerning democracy is itself protected by the democratic ideal of free speech ... [T] he First Amendment protects Baidu's right to advocate for systems of government other than democracy (in China or elsewhere) just as surely as it protects Plaintiffs' rights to advocate for democracy. ${ }^{38}$

If search results are no less than a way to 'advocate' for a cause, the same can be said of autocomplete suggestions. Through search results, the search engine 'expresses' its 'opinion' as to what information is relevant to the user in a particular search; similarly, through the autocomplete function the search engine expresses a further 'opinion' as to what is worth searching in the first place. Both are acts of free speech, and both are worth constitutional protection.

However attractive in its simplicity, this argument is flawed in some important respects and is based on a number of assumptions that are all but self-explanatory. First, it is questionable that the act of returning search results or search suggestions in response to queries can qualify as a 'statement of opinion' in the first place. Even within a judicial trend that has expanded the notion of 'speech' to include various instances of the so-called 'non-verbal communication'-such as symbolic speech,

intentionally deviate from its mathematical algorithm in decreasing Search King's PageRank may rise questions about the 'truth' of the PageRank system, there is no conceivable way to prove that the relative significance assigned to a given web site is false. A statement of relative significance, as represented by the PageRank, is inherently subjective in nature. Accordingly, the Court concludes that Google's Page Ranks are entitled to First Amendment protection (Search King, Inc. v Google Technology, Inc, 11).

Langdon v Google, Yahoo! and Microsoft Corp., 474 F Supp 2d 622 (D Del 2007). To the plaintiff, the removal of a website from search results merely on the ground of its politically inconvenient content was in contradiction with the express Google's policy statements that their search results are objective and neutral, and made Google's content policy fraudulent and deceptive. The lawsuit concerned two websites, one exposing fraud perpetrated by various North Carolina officials and one delineating atrocities committed by the Chinese government.

36 ibid. The court relied on the principle that the right of free speech guaranteed by the first amendments 'compris[es] the decision of both what to say and what not to say' (Riley $v$ National Federation of the Blind of North Carolina, Inc. (1987) 487 US 781, 796-97). 
commercial and functional messages - the construction of pure algorithmic outputs as 'opinions' remains problematic. As Tim Wu convincingly argues, a fully inclusive theory of the First Amendment that treats as 'speech' anything that can be labelled as an 'opinion' simply because it 'sends a message' to an audience, is 'hopelessly overbroad' and eventually impracticable. ${ }^{39}$ For instance, such a construal does not allow to make a distinction between purely functional 'messages', such as the sound of a car alarm or the instructions provided by a GPS sat nav, and expressive messages properly so called. ${ }^{40}$

Secondly, the analogy between search engines and media publishers, on the ground that both subjects select and choose the information they present to the public, is not entirely appropriate. What confers the status of 'speaker' to a newspaper or to a broadcaster is not just the fact of selecting what to present and how to present it, but, most importantly, the fact of 'endorsing' the information which is presented. ${ }^{41}$ The media publisher 'owns', in a way, the information it presents to the public, while this is not true for a search engine. To be sure, there is not, nor there can be, endorsement over the information contained in the websites a search engine ranks. In our view, it is equally questionable that the search engine 'owns' or endorses the autocomplete search suggestions. This is because autocomplete suggestions are based on automated processing of 'users" searches; they are not independent and autonomous outputs of the search engine's algorithm.

Curiously enough, as we will discuss later on in this article, a number of courts in Europe have dismissed claims against Google precisely because the suggested word associations in Instant Search are 'not' 'speech' in the first place, and therefore are not capable of conveying a meaning-let alone a defamatory or libellous meaning. ${ }^{42}$ What constitutes a possible defence under US law may result in liability under the laws of EU countries.

\section{SEARCH SUGGESTIONS AS SPEECH THAT CANNOT BE PROTECTED: BALANCING THE TORT OF 'FALSE LIGHT' AGAINST THE FIRST AMENDMENT}

While search suggestions may be constitutionally protected as sui generis forms of speech, they nevertheless may be actionable inasmuch as they contain either a provable false factual connotation or an otherwise misleading message, thereby triggering a tort of 'false light'. This is what happened in a case brought by a medical doctor before a US District Court in California. ${ }^{43}$ According to the complaint, when someone typed 'Guy Hin ...' into the Google search bar, the words 'Guy Hingston Bankrupt' appeared, even though the search results directed to articles that had absolutely nothing to do with a bankruptcy associated with Dr Hingston. The latter non-verbal communication acts and (non-protectable) conduit, see J Thomas dissent in Virginia v Black (2003) 538 US 343.

40 ibid 1518-21 (arguing that US jurisprudence contains an implicit 'functionality doctrine', whereby functional elements of a communicative act are not protected by the First Amendment).

41 ibid 1528.

42 See below, Section 6.2.

43 Guy Hingston v Google Inc, US District Court, SACV 12 - 02202 JST (AN x). 
contended he has never gone bankrupt, and that this deceptive association generated by Instant Search has resulted in loss of clients.

The plaintiff voluntarily dismissed his claims before the court could rule on the merits of the case. Despite the fact that the suggestion contained a provable false factual connotation, it is dubious whether such a claim could succeed. There are three main reasons for this, all related to the particularity of defamation laws in the USA. First it is not clear whether the publication will be found to be 'in false light'. This is a notoriously ambiguous tort and whereas Californian law shares similarities with defamation, it does not require a false statement of fact but a false implication of fact. ${ }^{44}$ What is important for a successful complaint is that the publication must identify or be 'of and concerning' the plaintiff. Internet users are aware that personal names featuring in search results may refer to different persons, and the very possibility that there is somewhere another Guy Hingston that has gone bankrupt implies that a reasonable user would not be confused. ${ }^{45}$ We ought to keep this consideration in mind, as we will discuss later on the ways in which names, in addition to some other information, qualify as personal data. Secondly, for a publication to be actionable in false light there is need for probable falsity. Here the court has to balance the claim of false light against the First Amendment right of free speech of the search engine. If the statement 'cannot be read to imply the assertion of an objective fact', the plaintiff's claim will fail. ${ }^{46}$ This means that the plaintiff ought to demonstrate that the search terms are assertions of such objective facts and this may be hard to establish, as the terms appear in the context of searches performed by users. Thirdly, if the suggestion points to factual connotations contained in third parties' websitesfor instance, websites where the words at stake are in one way or another associated-then the claim may fall foul of the Communication Decency Act. ${ }^{47}$ According to section 230 of this Act, 'no provider or user of an interactive computer service shall be treated as the publisher or speaker of any information provided by another information content provider'.

In Parker $v$ Google, the court rejected the claims of defamation, invasion of privacy and negligence against Google for making third-party defamatory content available via search results, on the ground that ' $[\mathrm{i}] \mathrm{t}$ is clear that section 230 was intended to provide immunity for service providers like Google on exactly the claims Plaintiff raises here. ${ }^{48}$ The same argument was adopted in Stayart $v$ Yahoo, where the plaintiff raised claims of false endorsement and violation of the right of publicity against Yahoo!, Alta Vista and Friendfinder. ${ }^{49}$ When the plaintiff put her name into Yahoo! and the other search engines, she found herself linked to 'a sexual dysfunctioning drug, hard-core pornographic websites, and an on-line pharmacy promoting Cialis ${ }^{\circledR}$ '. To the court, however, the plaintiff failed to demonstrate that she had a commercial

45 See eg Tamkin v CBS Broadcasting Inc, 193 Cal App 4th 133, 146-47 (the fact that a fictional character had the same name with the plaintiff did not suffice to demonstrate that the work refers to the plaintiff).

46 Partington v Burliosi, 56 F 3d 1147, 1157 (9th Cir 1995).

4747 USC s 230.

48 Parker v Google, Inc., 422 F Supp 2d 492, decision summary aff d, 242 Fed Appx 833 (3d Cir 2007), cert denied 522 US 1156 (2008). 
interest in her name, and therefore had no standing under section 43(a) of the Lanham Act. ${ }^{50}$ As no intellectual property offence could be demonstrated, the defence of section 230 wholly applied and the case was dismissed.

With regards to autocomplete suggestions, it could be argued that search engines are exempt from liability under section 230 insofar as the word associations reflect content appearing in the search results. It is only when the suggestion objectively points to a false statement that the search engine may be obliged to remove it. No general obligation to comply with requests of removing words associations can be inferred from US law.

While the analogy with media enterprises may discharge search engines from liability in the USA, on the ground of the likely constitutional protection of search suggestions as acts of speech, it may have the opposite effect in other jurisdictions where laws impose more strict conditions on public speech. This is notably the case for defamation law in the UK, where a higher standard of common law liability is imposed on 'publishers' as subjects who have control over content. ${ }^{51}$

\section{THE TORT OF DEFAMATION: IS A SEARCH ENGINE A 'MEDIUM' OR A PUBLISHER?}

The discussion as to what search 'facilitation' includes becomes central in deciding whether the search engine functions as a publisher or as an innocent intermediary. Despite the fact that suggestions are algorithmically generated and collated on the basis of certain objective factors, it can be argued that it is the search engine that is their publisher. This is because it would only be the search engine to know details of the numbers of Internet users typing a particular search and other relevant information, even though it is each individual Internet user that 'activates' the algorithm by entering the query. Obviously, the search engine operator cannot have control on each and every suggestion or list of results that it is generated on millions of users' screens. It has, however, the capacity of excluding certain word associations from appearing, as policy filters demonstrate. Therefore, it is reasonable to assume that, after having received notification of a given association, the search engine becomes aware that the algorithm produces such an association and is in a position to take action. Is this awareness sufficient to qualify the search engine as a 'publisher' and then fix it with liability for publishing defamatory associations?

In the UK, there is a long established line of authority that a person involved only in dissemination is not to be treated as a publisher, unless two conditions are met. First, to qualify as a publisher, the person must have an intention to publish the content, and should not merely play a passive intermediary role. ${ }^{52}$ The second condition is that they should have either actual or constructive knowledge of the content of the publication, namely, in case of defamation, that they knew or ought to have known

50 The court also refused to allow the plaintiff to re-plead her complaint and proceed on statutory and common law invasion of privacy 'on the ground of futility' (ibid 24-25).

51 Andrew T Kenyon, Defamation: Comparative Law and Practice (Routledge-Cavendish 2006); Elizabeth Samson, 'The Burden to Prove Libel: A Comparative Analysis of Traditional English and U.S. Defamation Laws and the Dawn of England's Modern Day' (2012) 20(3) Cardozo J Intl Comp Law. 
by the exercise of reasonable care that the publication was likely to be defamatory. ${ }^{53}$ If one of these conditions is not met, the defence of 'innocent dissemination' can be invoked. This standard applies also with respect to Internet service providers and search engines. In Bunt $v$ Tilley, ${ }^{54}$ it was found that, to establish liability, there must be a 'mental element' that cannot be established in instances where the service provider performs no more than a passive role in facilitating Internet access. ${ }^{55} \mathrm{~A}$ similar test was applied in Metropolitan International Schools Ltd $v$ Designtechnica Corpn ${ }^{56}$ in relation to defamatory comments that, having been posted on a website, appeared as 'snippets' of information when an Internet search took place under the claimant's name on Google search engine. The Judge found that for a person to be responsible for publishing defamatory words there needs to be a mental element, which was absent in this case. This is because the search is performed automatically and involves no input from the search engine, 'which had not authorised or caused the snippet to appear on the user's screen in any meaningful sense but had merely by the provision of its search service played the role of a facilitator. ${ }^{57}$

The situation changes, however, once the 'facilitator' receives information that defamatory content has been published through its services. Common law instructs that a person can in principle be liable for the publication of libel by acquiescence, ie by permitting publication to continue, on condition that he or she has the power to prevent it. ${ }^{58}$ In this connection, search engines differ from other Internet service providers (ISPs) such as hosting services, as they have no power of control over the content that appears in search results. On this basis, Eady J in Metropolitan found that it is 'hardly possible to fix Google Inc with liability on the basis of authorisation, approval or acquiescence. 59

This argument was considered in Tamiz v Google, where the Court of Appeal faced the question of whether Google is a publisher of certain defamatory comments appearing on a blog hosted on the Blogger platform. ${ }^{60}$ Google, in the context of Blogger, acts as a hosting service, not as a search engine: it provides a platform for the blogs along with advertising and hence it has control over them. Its involvement is not such, however, as to qualify it as a primary publisher of the blogs, ie vicariously liable for its users. Nor is it a secondary publisher facilitating publication as a distributor. However, these considerations change when Google receives notification. According to Richards LJ, 177-80; Bottomley v FW Woolworth and Co Ltd (1932) 48 TLR 521.

54 Bunt $v$ Tilley [2007] 1 WLR 1242.

55 ISPs who did not host a website were found to have a passive instrumental role and to be liable they ought to have 'a knowing involvement in the process of publication of the relevant words' (ibid s 23). See also Tamiz v Google [2013] EWCA Civ 68 s $18 \mathrm{ff}$. were the Judge made an analogy between Blogger and a graffiti wall 'festooned overnight with defamatory graffiti'.

56 Metropolitan International Schools Ltd v Designtechnica Corpn [2011] 1 WLR 1743.

57 Tamiz (n 55) s 20.

58 See the cases quoted above, $\mathrm{n} 53$.

59 Metropolitan International Schools Ltd (n 56) s 58.

60 Tamiz (n 55). 
'if Google Inc allows defamatory material to remain on a Blogger blog after it has been notified of the presence of that material, it might be inferred to have associated itself with, or to have made itself responsible for, the continued presence of that material on the blog and thereby to have become a publisher of the material'. 61

In Tamiz, hence, Google could not benefit from the defence of section 1 of the Defamation Act 1996 because after notification they knew or had reason to believe that their continued hosting of the materials caused, or contributed to, the publication of a defamatory statement. ${ }^{62}$

In a case that was brought before the Supreme Court of Virginia in Australia, ${ }^{63}$ Beach $\mathrm{J}$ found that once a search engine knows of a complaint of defamation, it can be treated as a publisher of that content, if it does not remove the offending material within a reasonable time. The case was brought against Google by Mr Trkulja, after discovering that his name was linked to criminal activities and Melbourne's underworld in Google's web and images' search results. Curiously enough, this link was accidentally generated by websites reporting an event that occurred to the plaintiff some years before as he was victim of an onslaught in a restaurant of Melbourne. In finding for the plaintiff, Beach J concluded that Google intended to publish the material produced through its automated systems, because that is what they are designed to do upon a search request being typed into the search engine. ${ }^{64}$ Awarding the plaintiff the sum of $\$ 200,000$, Beach J held that:

[t]he question is whether, after relevant notice, the failure of an entity with the power to stop publication and which fails to stop publication after a reasonable time, is capable of leading to an inference that that entity consents to the publication ... Further, if that inference is drawn then the trier of fact is entitled (but not bound) to conclude that the relevant entity is a publisher. $^{65}$

What Trkulja, Tamiz, Davison and Metropolitan International Schools instruct is that search engines cannot be considered as publishers unless two conditionstranslating the common law requirements of 'power of control' and 'mental element' - are met, namely (i) the search engine 'hosts' the allegedly defamatory material (and does not only 'direct towards' it), and (ii) it receives 'notification' of the defamatory content. Once these conditions are met, the search engine can escape liability only if it acts to remove the content within reasonable time.

61 s 34. The judge took into account Byrne v Deane [1937] $1 \mathrm{~KB} 81$ (Deane (defamatory content left on the notice board of a golf club amounted to participation in publication) and cases that repeated the same principles, such as Davinson v Habeeb and Others [2011] EWHC 3031 (QB) (Google's role in relation to Blogger was that of a 'provider of a gigantic noticeboard on which others published defamatory material').

62 A similar outcome would have likely been reached under the Defamation Act 2013, according to which the term 'publisher' has the same meaning as in section 1 of the Defamation Act 1996 (art 10(2)).

63 Milorad Trkulja v Google Inc LLC (No 5), No 10096/2009, [2012] VSC 533.

64 Above s 18.

$65 \mathrm{~s} 31$. 
Relevant in this regard are the EU provisions on e-commerce and in particular the immunities offered to Internet service providers for caching and hosting content online.

\section{INTERMEDIARY LIABILITY: WHEN DO THE E-COMMERCE DEFENCES WORK?}

Under EU Law, a search engine can rely on two main defences for information society services, namely caching and hosting. Caching is the 'automatic, intermediate and temporary storage' of information in the course of a communication between third parties, whereas hosting is the 'storage of information provided by a recipient of the service'. By reference to the search engine service we are considering in this article, the main difference between the two defences is that the hosting defence requires that the service expeditiously removes illicit content upon obtaining knowledge or awareness of it. The caching defence, by contrast, only requires that the service removes or disables access to content when it receives actual knowledge that the content has been removed from the network, or when a court or an administrative authority orders the removal. ${ }^{66}$

The availability of these defences for search suggestions has been extensively discussed by national courts of European countries, where they have been balanced against diverse national doctrines on direct and indirect liability to reach, in some instances, divergent outcomes. Given the lack of harmonization in many of these underlying doctrines - tort law, defamation, personality rights, etc. - it is no surprise that the immunities provided by the e-commerce directive are not applied consistently across European countries, leaving strong discrepancies not only between common law and civil law jurisdictions, but also within civil law systems. ${ }^{67}$ Perhaps more interestingly, the immunities may also apply differently, within the same jurisdiction, to different torts committed by means of autocomplete, namely defamation, copyright infringement or breach of data protection law. In the following, we examine the trends in civil law jurisdictions, by considering how claims on defamation and damage to business reputation have been dealt with by a number of European courts.

One of the leading judicial trends focuses on the specificity of the autocomplete function compared to the 'standard' operations routinely performed by search engines. In this respect, the courts' reasoning is premised on 'unpacking' the services offered by the search engine operator and taking autocomplete as a separate feature with its own characteristics. While indexing and linking to web pages in search results do not normally imply liability as to the content that the users search, the autocomplete function introduces, in the search process, an additional source of informative content of which the search engine is solely responsible. By suggesting search queries and related searches, the operator of a search engine is no longer a mere facilitator or

66 Dir 2000/31/EC on e-commerce, arts 13 (caching) and 14 (hosting). For a thorough discussion in relation to defamation see Jan Oster, 'Communication, Defamation and Liability of Intermediaries' (2015) 35(2) Legal Stud 348.

67 For a thorough discussion in relation to copyright law see Christina Angelopoulos, 'Beyond the Safe Harbours: Harmonising Substantive Intermediary Liability for Copyright Infringement in Europe' (2013) 3 IPQ 253. 
a technical distributor of information but it takes on an active role and is liable as such for the message conveyed by its service. Specifically-depending on the vernaculars of national laws - the search engine operator may be treated as a publisher, an interferer (Störer) or a content provider (fornitore di contenuti). So far, the most authoritative decision in this line of cases is a judgment laid down by the German Federal Supreme Court in 2013. ${ }^{68}$

On the contrary, courts have denied search engine liability based on two main arguments, frequently working in tandem. One is that the algorithm simply reflects the popularity of users' searches, and is therefore a neutral technical instrument that does not express 'what Google thinks'. As a consequence, the disputed suggestion is not illicit content, since lists of suggestions and related searches are per se devoid of any inherent meaning: they are tools to facilitate the search, and Internet users understand that they have this function. The second argument is that a duty to remove search suggestions would impose obligations that are not compatible with the functioning of a search engine, or that would unduly restrict freedom of information. This line of reasoning, too, has found support in Supreme Court, and in particular in the judgments of the French Cour de Cassassion in July 2012 and in February 2013. ${ }^{69}$

We discuss the two opposite judicial trends and their implications on search engine liability separately.

\subsection{When the search engine is liable: isolating the autocomplete effect and applying the 'user expectation' argument}

As exemplary of the argument developed by European courts to refuse immunity under the e-commerce Directive, we can consider a decision of the Tribunal of Milan, Italy, in $2011 .^{70}$ In this case the focus was on the liability of a search engine under the safe harbour provisions for caching and hosting. ${ }^{71}$ The claimant brought proceedings against Google on the basis that his name and surname featured next to the words 'truffatore' and 'truffa' (scam, fraud) when users typed the name in the search bar. The court found that the hosting defence could not apply since, in its view, the defence covers exclusively 'the activity of the storage of information provided by others'. To the court 'this kind of complaint is not about the hosting activities of Google, but about ... an association which, clearly, is the product of a specific way of working ... a software developed by Google'. ${ }^{72}$ To conclude that the search engine was liable for the particular defamatory word association, the court stressed its role in developing the 'related searches', which is part of the autocomplete service. It was found that Google is hosting the combined results of all of its users' searches, and is in turn making them available to other users. This activity qualifies as 'storage of information provided by a recipient of the service' within the meaning of the Directive. However, the provision of automatically produced

68 BGH, Case No VI ZR 269/12 of 14 May 2013. See discussion below, nn 84-88 and accompanying text.

69 Google/Lyonnaise de garantie (n 4); Pierre B./Google Inc (n 5). See discussion below, nn $89-94$ and accompanying text.

$70 A B v$ Google, Tribunale Ordinario di Milano, 24 March 2011.

71 D Lgs 70/2003, arts 15 and 16 (corresponding to arts 13 and 14 of the e-commerce Directive).

72 ibid. 
suggestions based on this information is a conscious and commercially focused decision made by the company, which exceeds the mere hosting of users' searches. ${ }^{73}$

In a case heard two years later on similar facts, the Court of Milan further clarified the interpretation of the hosting defence. ${ }^{74}$ Citing CJEU's L'Oreal $v$ EBay in support, ${ }^{75}$ the court explained that the immunities provided by the e-commerce Directive have a character of 'exceptionality', which must not be construed extensively. In the court's opinion, exclusions from liability must be 'limited to situations where the service provider is a mere intermediary of the information, totally unrelated to the content and thereby completely passive with respect to the content transmitted by third parties on the internet'. ${ }^{76}$ After setting such a high threshold for immunity, the court moved on to consider the autocomplete function in the framework of Google's activities as a hosting service and coined the definition of 'active hosting': by this, it referred to a service in between a content provider and a passive and neutral intermediary, but one that could in any case be unable to invoke the hosting defence. Although word associations generated automatically by the autocomplete function are not 'logically and grammatically complete sentences', they may nevertheless 'suddenly evoke a meaningful concept or information' related to the searched subject. The injunction must be specifically targeted to associations capable of evoking information with defamatory content. ${ }^{77}$

The assumption that search suggestions and related searches are fully fledged 'informative content', and not simply the neutral reflection of users' habits, underlies many of the rulings against Google in other jurisdictions too. In Direct Energie, the Tribunal de Commerce of Paris found that the association of a company's name with 'arnaque' (scam) as first in a list of 10 search suggestions engenders as a minimum 'the suspicion of a commercially questionable behaviour' on the side of the company. This is even more so, as the suggested term is not contained in the search result featuring in the first position, nor is the first in alphabetical order. ${ }^{78}$ This way, Google takes part (albeit involuntarily ${ }^{79}$ ) to a 'derogatory campaign against Direct Energie' and, in this connection, the request of removal is not unjustified or disproportionate in relation to freedom of expression.

In another French ruling on similar facts, ${ }^{80}$ the argument of a possible conflict with freedom of expression was dismissed on the ground of a surprisingly narrow interpretation of such freedom: to the court, a literal reading of Article 10 of the

A similar conclusion was reached in the French case Mme C/Google France (n 5).

Tribunale di Milano, Ordinanza 23 May 2013.

L'Oréal SA and Others v eBay International AG and Others, Case C-324/09, 12 July 2011.

Tribunale di Milano (n 74) 6-7 (emphasis added).

In this case, the court found that the association of the name of a private person with the terms 'sect' and 'brainwashing' in the context of internet searches did not 'induce immediate elaboration of a definite concept', and therefore cannot have defamatory meaning; by contrast, the association of the name of a legal person (in this case, a foundation) with the same words 'renders immediately a full meaningful concept, namely that the legal entity in question is a sect'.

Direct Energie/Google, Tribunal de Commerce de Paris, Ord 7 May 2009.

The 'good-faith excuse' was found prevailing in Pierre B./Google Inc (n 5). See discussion below, nn 95-98 and accompanying text.

Bruno L., Resources et actualisation/Google Inc., Google France, (n 14) (person's and company's name associated with 'escroc' [swindler] and 'secte' [sect]). 
Convention for the Protection of Human Rights and Fundamental Freedoms makes clear that 'freedom of expression' is a right that applies to 'persons', and cannot be invoked to protect the automated functioning of a search engine application. ${ }^{81}$ The fact, however, that the laws applicable to human thinking cannot apply to machinegenerated content, does not lift the owner of such machine from civil liabilities. Specifically, the court observed that the adjective 'pertinente' (related), which is used to qualify the automated search, ${ }^{82}$ induces users to believe that the suggestions are topical to the subject, so that the suggested terms obtain a value that goes beyond the popularity of searches. In this connection, the lack of information about the flawed character of related searches and the search suggestions resulted in the tort of negligence as per article 1383 of the French Civil Code. ${ }^{83}$

In all these rulings, courts have resolved the issue of whether automatically generated search suggestions can have defamatory meaning by shifting the focus from the 'source' of the content (ie the algorithm that generates the suggestions and the related searched) to the 'recipient' of the information (ie the Internet user). In this respect, a key element in the assessment of the defamatory effect of search suggestion is the expectation that search engines generate on users. This element is at the heart of the German Federal Supreme Court decision of $2013 .{ }^{84}$ In this case, the claimant, who owed a cosmetics company under his name, found that his name was associated with the words 'scientology' and 'fraud'. Overturning two earlier decisions, ${ }^{85}$ and quashing the findings of a number of German lower courts, ${ }^{86}$ the Federal Supreme Court found in favour of the claimant. It held that Google was liable for not having removed false associations upon receiving notification from the claimant. Mere word associations have the capacity of being defamatory as such, and they can convey a meaning irrespective of whether they are read in conjunction to search results or not. The autocomplete function creates an expectation to Internet users: because the algorithm-driven search program incorporates the searches previously made by other users, and presents current users with the combination which is most frequently appearing in search results, users expect that 'the search queries completed through the suggested word combination reflect content-related relationships. ${ }^{87}$ Otherwise put, the word association has an informative meaning-despite the fact that there may not be search results confirming this association-because users expect that the associations are informed by real content indexed by Google.

81 ibid. The incipit of art 10 reads in French: 'Toute personne a droit à la liberté d'expression' (emphasis added). The reading of the court is narrow, in the sense that it disregards the right to receive information as constitutive to freedom of expression (alongside the right to impart information). Compare the US jurisprudence on freedom of speech discussed above, Section 3.

82 The Court referred specifically to the Google's information page on Autocomplete <https://support. google.com/websearch/answer/106230?hl=fr> accessed 20 May 2015.

83 Bruno L., Resources et actualisation/Google Inc., Google France (n 80) 5.

84 BGH Case VI ZR 269/12 of 14 May 2013. For a comment: Karl-Nikolaus Peifer 'Google's Autocomplete Function-is Google a Publisher or a Mere Technical Distributor?' (2014) 3 QMJIP 318.

85 LG Köln, 28 O 116/11, 19 October 2011 and OLG Köln (n 6).

86 OLG Hamburg ( $\mathrm{n}$ 4) ('Internet users do not assume search results are statements of the search engine'); OLG Munich, 29 U 1747/11, 29 September 2011 (Autocomplete is a purely automated process; there is no 'own expression of content' by Google). 
On the basis of this 'expectation' argument, the court maintained that the predictions generated by the algorithm are ISP's 'own information', and not information stored at the request of the recipients of the service. While the hosting defence cannot apply, the court nonetheless recognized that Google, as a 'technical' instead of 'intellectual' distributor, ${ }^{88}$ has a duty to react upon receiving knowledge that given information is breaching personality rights. It does not, however, have a general obligation to search for infringements committed by the autocomplete algorithm.

\subsection{When the search engine is innocent: the functional approach to autocomplete or the 'mere facilitation' argument}

The legal effect of the lack of human intervention in the production of search suggestions is one of the most controversial points challenging European courts. In two decisions of the French Supreme Court (Cour de Cassation), the charge on Google was dismissed on the ground that word combinations generated by the autocomplete function are not an expression of thought or intellectual reasoning, but a technical method to facilitate the search. ${ }^{89}$ This means that no defamation complaint can flourish, as defamation laws, to apply, require the expression of an opinion. We will call this the 'functional approach' to autocomplete search suggestions. According to this approach, the combination of words is devoid of any meaning and does not imply the intention to link one word to another. ${ }^{90}$

Lyonnaise de garantie was a case on the association of the name of a company with 'escroc' (fraud) in the third place of the list of suggested searches. Reversing the decisions of two lower courts, ${ }^{91}$ the Cassation found that word combinations in the context of search suggestions have no autonomous meaning since they do not represent a judgment or opinion. ${ }^{92}$ It moved on to stress that the filters that Google applies, for instance, on pornographic content are not relevant or sufficient to give autonomous meaning to word associations. ${ }^{93}$ Hence, it concluded that 'the automatic and instantaneous display of keywords in the search bar is devoid of any intrinsic meaning and constitutes a mere search tool for internet users, and one that directs them to websites that may contain the keywords, ${ }^{94}$

The same conclusion was reached in an earlier case, where infringement of personality rights was discussed. ${ }^{95}$ Here the claimant was a private person who had been involved in a case of corruption of a minor, for which he received a three-year sentence in 2010. When entering his name on Google search bar, suggested words such as 'viol' (rape), 'condamné' (sentenced) and 'sataniste' (Satanist) appeared, and the

Under German Law, strict liability is imposed only to 'intellectual distributors', while mere technical distributors are only liable insofar as a causal element can be established between the 'interference' to the dissemination and the infringement (Störerhaftung). See Peifer (n 84) 323.

89 Pierre B./Google Inc (n 5); and Google/Lyonnaise de garantie (n 4).

90 A similar conclusion was also reached in Omnium Finance/Google and JFG Networks, TGI Paris, 22 July 2010 ('Google suggest . . . appears to the user as a tool to help the search ... and not as a statement of the search engine vis-à-vis the plaintiff).

91 TGI Paris, 18 May 2011 and Court of Appeal of Paris, 14 December 2011.

92 Google/Lyonnaise de garantie (n 4) 5-6.

93 ibid 6, point 4.

94 ibid 6.

95 Pierre B./Google Inc (n 5). 
claimant requested an injunction to remove these allegedly defamatory suggestions. The claim was upheld by the first instance court, ${ }^{96}$ but dismissed in appeal. ${ }^{97}$ Confirming the decision of the Court of Appeal, the Cassation held that, when assessing the intentional element of defamation, 'due account' should be taken to the 'functionality' of the autocomplete suggestions:

although the expressions [denounced by the claimant] are in a literal sense defamatory, at the stage of the assessment of the mental element [of defamation] they must be considered according to their functionality, which is to facilitate the access to websites dealing with or considering the issue addressed in the expression. ${ }^{98}$

Here the court draws a distinction between the 'literal sense' of a word association and its 'functionality' once it appears in a technical tool whose sole purpose is to facilitate search and access to websites. In the latter case, the meaning of the association-if any - can only be revealed after the search has taken place. No infringement of personality rights can be ascribed to the service that provides this functionality.

We will discuss later the question whether this argument is tenable from a data protection perspective, especially in the light of the broad scope given by the European Court to the notion of unlawful data processing. ${ }^{99}$ For now, we can observe that the position developed by the French Cassation Court-setting aside the literal meaning and focusing only on the functional element of the automated word association-develops a line of reasoning that deprives word associations from any intrinsic meaning. According to this position, algorithmically generated predictions merely enable easier navigation of the web. There is no user expectation to be assumed as to the credibility of the suggestions, as in the German jurisprudence. The search engine defence on lack of human intervention weighs heavily in this judicial stance, which adopts a purely instrumental theory as to the nature of automated word associations. The function of the algorithmic search suggestion tools becomes hence primordial in understanding the value and legal implications of automated word suggestions. Since its purpose is recognized as lying on the facilitation of Internet search, same is the purpose and function of algorithmically generated word combinations, with nothing more to be assumed than the functional value that they hold. As we will see later, the 'facilitation' argument may lead to the opposite conclusion when the claim is directed to infringement of intellectual property rights: in this connection, 'facilitating' access to illegal websites may be sufficient to charge the search engine with indirect liability. ${ }^{100}$

TGI Paris, 8 September 2010. To the court, the word association, although merely functional to the retrieval of 'real' search results, was defamatory at least 'by insinuation'. The Court also found that the suggestions are not purely dependent on algorithmic calculations, but include some discretionary elements, as demonstrated by the fact that the same search on Yahoo! provides completely different suggestions.

97 CA Paris, 14 December 2011.

98 Pierre B/Google Inc (n 5).

99 Google Spain SL (n 10). See discussion below Section7.

100 See below Section 9. 
Yet, in the context of infringement of personality rights, the argument that mere word associations have no independent meaning is also reflected in other national courts' decisions, namely in Italy and Switzerland. In Italy, the First Instance Court in Pinerolo found that 'the mere association of words in a search string is not a statement but, depending on the purpose of the software, it is better assimilated to a question'. ${ }^{101}$ Word associations may embed opinions and hence have a derogatory meaning only in instances where the fact is not true 'and' the question is either rhetorical or maliciously asked. In the present case, the name of the plaintiff was automatically associated with the words 'arrestato' (under arrest) and 'indagato' (under investigation). The Court of Pinerolo held that these suggestions cannot as such damage the reputation of the claimant because 'the context in which the word associations appear in the Google search bar excludes that the question is a rhetorical one or one that has maliciously been asked'. It moved on to observe that even the less informed Internet users could not have been misled since the results of the search performed using the suggested terms make clear that the plaintiff has neither been arrested nor is subject to investigation.

Similarly, the Court of Milan too rejected the claimant's argument that Google is a content provider and hence responsible for the allegedly defamatory terms 'setta' (sect), 'plagio' (brainwashing) and 'truffa' (scam) featuring next to the claimant's name, and that of the charity organization bearing his name. ${ }^{102}$ Here the Judge found that Google is acting as a caching service, rather than as a content provider, and on this basis it can benefit from the relevant exemption incorporated in the e-commerce Directive. ${ }^{103}$ The automated suggestions are algorithmically determined, and hence do not fall under Google's control in the sense of being structured, organized or influenced.

This functional approach has been upheld by a lower court in Switzerland too, where the breach of personality rights has been balanced with concurring private and public interests, and in particular the constitutional right of freedom of information. ${ }^{104}$ Contrary to the findings of lower French Courts on the same point, ${ }^{105}$ the Cantonal Tribunal of Jura found that imposing an obligation to remove suggestions that are threatening to one's own personality right 'would impose to search engines an obligation which is not proportionate and which would restrict inadmissibly the right to information'. This is because search engines would be obliged to intervene 'without having the capacity to verify the legitimacy or not' of a request and 'under risk of incurring civil or even criminal liabilities for not intervening'. To the court, such an obligation 'would make almost impossible the management of a search engine and, consequently, the use of the Internet, thereby bringing a serious offence to the right of information'. 106

$102 X$ c. Google, Tribunale Ordinario di Milano (n 4). Compare this decision with the opposite judgment expressed by the same court two years earlier on 24 March 2011 (see discussion above nn 70-73 and accompanying text). 
Beyond defamation, claims of violations of data protection law can also be made. The question of whether an obligation to remove search results is a proportionate limit to freedom of information and freedom of doing business is at the core of the decision of the CJEU in Google Spain v AEPD. ${ }^{107}$

\section{SEARCH SUGGESTIONS WITH NO FALSE FACTUAL MEANING: DATA PROTECTION AND THE 'RIGHT TO BE FORGOTTEN'}

In a very controversial judgment, which stands in sharp contrast to the opinion of the Advocate General, ${ }^{108}$ the European Court responded to the question in the affirmative: the right that personal information, which is irrelevant or out of date should not be made available to the public by its inclusion in search results

'override(s), as a rule, not only the economic interest of the operator of the search engine but also the interest of the general public in finding that information upon a search relating to the data subject's name'. ${ }^{109}$

The scope given by the European Court to this right is remarkably broad: it covers instances where personal information has been initially made available on the Internet legitimately, or where the information is true, ${ }^{110}$ as well as instances where the inclusion of the information in search results does not cause any prejudice to the person. $^{111}$

The basis for such a broadly construed personal right is the so-called 'right to be forgotten', as encompassed in the rights to erasure and blocking of personal data provided for in Article 12 of the Data Protection Directive. ${ }^{112}$ To the court, the activity of indexing, storing and making available in search results web pages that incidentally contain personal data is 'processing' of those data, and the operator of the search engine is the 'controller' of those data within the meaning of the Directive. ${ }^{113}$ As such, the operator of a search engine is bound by all the obligations that the Directive imposes on data controllers, specifically the duty to comply with the principles of data quality (Article 6) ${ }^{114}$ and with one of the criteria for legitimate data

107 Google Spain SL (n 10).

108 Opinion of Advocate General Jääskinen, Case C-131/12, 25 June 2013.

109 Google Spain SL (n 10) s 97.

110 ibid, ss 93-94.

111 ibid, s 99.

112 Dir 95/46/EC. The 'right to be forgotten' is codified in the proposed data protection regulation; see Proposal for a General Data Protection Regulation, Brussels, 25 January 2012 COM(2012) 11 final, art 17 ('Right to be forgotten and to erasure'). For a comment see Giovanni Sartor 'The Right to be Forgotten in the Draft Data Protection Regulation' (2015) 5 IDPL 64. For a discussion on the compatibility of the right to be forgotten with US constitutional law, see Robert K Walker, 'The Right to be Forgotten' (2012) 64 Hastings LJ 257.

113 Dir 95/46/EC, art 2(b) and (d). In the Opinion of the Advocate General, the operations carried out by a search engine are a 'processing', but the operator of a search engine is not a 'controller' of personal data included on third-party web pages (Opinion of AG, Case C-131/12, ss 75 and 84-90). To the court, Google is a controller insofar as it determines the 'purpose and means' of data processing (Google Spain SL (n 10) s 33).

114 The principles set forth in art 6 are: (i) fairness and lawfulness, (ii) purpose limitation, (iii) proportionality, (iv) accuracy, and (v) limitation on data retention. 
processing listed in Article $7 .{ }^{115}$ In the context of the operations carried out by search engines, the most relevant criterion is the one established in Article 7(f), namely processing that is 'necessary for the purpose of the legitimate interests' of the data controller. The scope of this legitimate interest, which has to be balanced against 'the interests for fundamental rights and freedoms of the data subject', ${ }^{116}$ has been largely debated and is subject to controversy. ${ }^{117}$ In Google Spain, the court took the view that compliance with the 'legitimate interests' criterion in connection to search engine operations can only be determined on a case-by-case basis, in the context of either requests of erasure or blocking submitted by data subjects under Article 12(b) (encompassing the 'right to be forgotten'), or the exercise of the right to object data processing provided for in Article 14(a). These requests may be addressed by the data subject directly to the controller who must then 'duly examine their merits and, as the case may be, end processing of the data in question', 118 namely remove links to websites containing a particular information from the list of results that are displayed following a search made on the basis of the person's name. It is only when the data controller does not comply with the request that the data subject may bring the matter before the supervisory authority.

\subsection{The (short) life of algorithmic suggestions after Google Spain}

Although Google Spain is a decision on search results, its connection with autocomplete suggestions is straightforward. If search engines are 'controllers' of personal data that merely happen to be included in web pages, they are a fortiori controllers with respect to data submitted by users when entering a search query. In fact, when users enter a person's name in the search bar, the data is processed by the algorithm, which combines it with other information and displays a list of suggested searches that may in turn disclose other personal information. It is, therefore, reasonable to conclude that the obligations imposed by the CJEU with respect to search results extend to search suggestions as well. This is also because autocomplete suggestions may undermine, and even reverse, the effect of a removal of search results. Suppose - as in the facts of Google Spain - a data subject obtains the removal, from the list of search results that are displayed when users perform a search based on his name, of information lawfully published on the Internet. While the information no longer appears in the list of results, autocomplete may facilitate users to retrieve it by carrying out an alternative search using suggested words. What is relevant to the exercise of the right to be forgotten, as well as to the right to object specific data processing under Article 14(a), is the capacity to break the 'link' between one's own identity and particular information concerning their person. In this respect, the

115 These are: (i) consent of the data subject, or processing necessary; (ii) to perform a contract; (iii) to comply with legal obligations of the data controller; (iv) to protect vital interests of the data subject; (v) to perform public interest or official authority tasks; and (vi) to pursue a legitimate interest of the data controller.

116 Dir 95/46/EC (n 113) art. 7(f).

117 For an authoritative discussion see Article 29 Working Party Opinion 06/2014 on the Notion of Legitimate Interests of the Data Controller, Adopted on 9 April 2014. 
obligations should extend to any technical means that facilitates the reconstruction of such link.

The Google Spain decision expands the scope of requests for removal of autocomplete suggestions both in a procedural and substantial way. As we have seen, in the aftermath of Google Spain requests can be submitted directly to the operator of the search engine, who has a duty to examine their merits and react accordingly. ${ }^{119}$ All major search engine operators have already put in place a 'notice and take down' procedure, similar to the one adopted in some jurisdictions for claims on copyright infringement, to deal with requests of removal of search results. ${ }^{120}$ The complaint web forms we have examined do not include reference to autocomplete suggestions. ${ }^{121}$ It is only Google that has recently included, for users browsing from the EU, a separate procedure to request the exclusion of 'offensive' 'predictions'. ${ }^{122}$

From a substantial point of view, this recent change in Google's policy may have been enacted as a result of Google Spain, which extends the ground to request for removal to instances where autocomplete suggestions do not need to convey a defamatory meaning or false factual information. This is an important point, as the European Court recognizes to an extent a right to determine the way in which information about oneself is organized and presented to the public. A recent case, which follows up on litigation that started over seven years ago, indicates that applications to seek interim injunctive relief for misuse of personal information may be far more successful after Google Spain. It is the case of Max Mosley, the former head of Formula One involved in a British tabloid sex scandal in 2008. Mr Mosley's application for an injunction against News Group Newspapers was refused in 2008, on the ground that the relevant material-video footages of Mr Mosley engaging in sexual activities with prostitutes-had become so widely accessible that either the claimant no longer had a reasonable expectation of privacy in relation to it, or it would make little practical difference to accept his application. ${ }^{123}$ The Google Spain judgment,

119 The factors to be considered in this examination include the nature of the information, its sensitivity to the data subject and the interest of the public in receiving that information-an interest which may depend 'on the role played by the data subject in public life' (ibid, s 81). See also Article 29 Working Party Guidelines on the Implementation of the CJEU Judgment on 'Google Spain v AEPD and González' C-131/ 12, Adopted on 26 November 2014.

120 Google was the first operator of a search engine to adopt such a procedure, followed by Microsoft's Bing and Yahoo! For an analysis of Google's take down notice see Ben Allgrove and Ian Walden 'Google Responds to ECJ's Decision on the Right to be Forgotten' (2014) 9 WCRR 31.

121 See Google, 'Search Removal Request under Data Protection Law in Europe' < https://support.google. com/legal/contact/lr_eudpa?product=websearch>_accessed 20 May 2015; Bing, 'Request to Block Bing Search Results In Europe' <https://www.bing.com/webmaster/tools/eu-privacy-request> accessed 20 May 2015; Yahoo!, 'Requests to Block Search Results in Yahoo Search: Resource for European Residents' < https://uk.help.yahoo.com/kb/SLN24378.html?impressions=true > accessed 20 May 2015. Ask does not have in place a complaints form, but invites users to submit removal requests by email in its 'Privacy policy' <http://about.uk.ask.com/about/terms_conditions/privacy.html > accessed 20 May 2015.

122 <https://support.google.com/websearch/answer/106230?hl=en> accessed 20 May 2015. The 'take down' notice is available to users browsing from some jurisdictions only; for example, it is not available to users in the USA.

123 Mosley v News Group Newspapers Ltd [2008] EWHC 687 (QB) s 36. See, however, Mosley v News Group Newspapers Ltd [2008] EWHC 1777 (QB), where Mr Mosley obtained a judgment against News Group Newspapers and record damages. For a comment, see Angius McLean and Claire Mackey, 'Mosley v 
however, gave Mr Mosley a new opportunity to seek the removal of those photographs on the basis of the Data Protection Act and in Mosley $v$ Google, it was found that he has 'a viable claim which raises questions of general public interest, which ought to proceed to trial'. ${ }^{124}$

It is widely accepted that search engines have 'a decisive role in the overall dissemination ${ }^{125}$ of information about one's person. The way in which such information is organized, aggregated and presented by the search engine, for instance through lists of search results ordered by relevance-but also by suggesting searches that are relevant to a person-may enable users 'to establish a more or less detailed profile of the data subject'. ${ }^{126}$ In this respect, search engines not only organize and make information provided by others retrievable, but also supply a 'distinctive' and 'additional' layer of data processing, which enables Internet users to obtain 'a structured overview of the information relating' to an individual, 'and thereby to establish a more or less detailed profile of him'. ${ }^{127}$

\subsection{Balancing private and public interests}

Significantly, the right to be forgotten, broadly construed as a right to organize one's own information, cannot be overridden by a legitimate interest of the data controller: it can only be balanced against a 'preponderant interest' of the general public to access that information, specifically when the data subject plays a role in the public life. Does this limitation preclude public persons from relying on this ground to request the removal of search results or autocomplete suggestions? One such case, perhaps one that has attracted a greater level of publicity, is the case of Bettina Wulff, the wife of the former German Federal President. Mrs Wulff filed a defamation suit at the District Court of Hamburg against Google, on the ground that when typing her name in the Google search engine, the words 'Bettina Wulff escort', and 'Bettina Wulff prostituierte' resulted. ${ }^{128}$ The case was settled before trial, althoughwith the recent amendment of Google's policy on 'offensive predictions' in the aftermath of Google Spain-litigation may have not even been strictly necessary. What Google Spain instructs, however, is that special attention should be paid:

on the nature of the information in question and its sensitivity for the data subject's private life and on the interest of the public in having that information, an interest which may vary, in particular, according to the role played by the data subject in public life. ${ }^{129}$

News Group Newspapers Ltd: How Sadomasochism Changed the Face of Privacy Law: a Consideration of the Max Mosley Case and Other Recent Developments in Privacy Law in England and Wales' (2010) 32 EIPR 77.

ibid, s 80 . 
Balancing private and public interests in this connection implies an assessment of the role of the data subject in public life coupled with an assessment of the information as such. According to the Article 29 Working Party, the criterion of the 'role in public life' must be construed broadly, and does not cover 'public figures' only. ${ }^{130}$ With respect to public figures, there is a strong presumption against de-listing search results relating to them, unless the information is 'genuinely private'. The criterion is the one developed by the European Court of Human Rights in von Hannover $v$ Germany:

[A]lthough in certain special circumstances the public's right to be informed might even extend to aspects of the private life of public figures, particularly where politicians were concerned, this would not be the case-even where the persons concerned were quite well known to the public - where the [information] related exclusively to details of the person's private life and had the sole aim of satisfying the curiosity of a particular readership in that respect. In the latter case, freedom of expression called for a narrower interpretation. ${ }^{131}$

A case-by-case assessment would be hence necessary as the public may have an interest in the disclosure of certain private information related to a public figure, on condition that such an interest is not merely that of 'satisfying the curiosity. ${ }^{132}$ In the UK, for instance, there are a number of cases concerning the construction of the public interest when information about public figures is released. ${ }^{133}$ Essentially, courts engage in a balancing exercise that includes weighing the public interest in maintaining confidence against a countervailing public interest favouring disclosure. What is taken into consideration is not only the fact that someone is a public figure, but also the nature of the information as such. ${ }^{134}$

In cases where the data subject has no prevalent role in public life, courts will have to balance the right to be forgotten with the interest of public to receive information, if any. In two cases of this nature discussed before Google Spain, national courts have reached opposing conclusions. In Madame $C v$ Google, ${ }^{135}$ which is the first autocomplete case where data protection law was applied, a French court found that the association of a personal name with the word 'swallow' and the title of an adult movie where the plaintiff played a role when she was young and inconsiderate, amounted to disproportionate processing of personal information. The court fixed

Article 29 Working Party Guidelines on Google Spain (n 119) 13.

Von Hannover v Germany II Case Nos 40660/08 and 60641/08 (ECtHR, 7 February 2012).

$<$ http://ec.europa.eu/justice/data-protection/files/factsheets/factsheet_data_protection_en.pdf $>$ accessed 20 May 2015. For a comment: Violette Grac-Aubert, 'A Love and Hate Relationship? Recent Developments in Data Protection and Competition Law’ (2015) 36 ECLR 224.

See eg Campbell v MGN Limited [2004] 2 AC 457; Mosley (n 124); Douglas v Hello! Limited [2001] QB 867; for a comment see: Rachael Mulheron, 'A Potential Framework for Privacy? A Reply to Hello!' (2006) 69 MLR 679.

134 See eg Sedley LJ in Douglas v Hello! Ltd [2001] QB 967, s 137; Att.-Gen. v Guardian Newspapers (No 2) [1990] 1 AC 109, 282B-F; see also the discussion on public figures' 'reasonable expectation to privacy' in Campbell v MGN Limited [2004] 2 AC 457.

Mme C/Google France (n 5). 
Google with a duty to comply with Madame C's request to remove those associations on the basis of the right to oppose data processing. ${ }^{136} \mathrm{~A}$ similar claim brought before a German Court in 2013, however, did not succeed: an ex member of the secret police of the former East Germany, the infamous Stasi, requested removal from autocomplete of the association of his name with the word 'stasi'. ${ }^{137}$ The court rejected the claim on the ground that the search engine is not liable for the information published in third parties' websites, to which the plaintiff should address his claim.

Although this latter decision is likely to be unsustainable in light of Google Spain, not all claims grounded on the right to be forgotten are automatically expected to succeed. It will be seen how national courts will balance such a right against the public interest in receiving information. In a post-Google Spain case brought before a Dutch court, a claim on the ground of the right to be forgotten failed because the public interest in receiving the contested information was found to prevail. ${ }^{138}$ The plaintiff in this case was sentenced for attempted murder seven years before the case was heard, and his name was associated in autocomplete with the name of a wellknown crime journalist who covered the event where the plaintiff was involved. Google refused to comply with the removal request, and the court upheld Google's decision on the ground of balance of interests.

\section{LIABILITY FOR INTELLECTUAL PROPERTY INFRINGEMENT: TWISTING THE 'FACILITATION' ARGUMENT}

The downfall of the 'mere facilitation' argument discussed earlier ${ }^{139}$ rests within its very conceptual construction: since the autocomplete function is meant to direct users to search results indexed by a search engine, its value as a defence loses its strength when the word associations direct users to potentially infringing content. This was found to be the case in SNEP, ${ }^{140}$ where the 'mere facilitation' argument took a strange twist. Repeating that word associations have no autonomous meaning and are meant simply to facilitate Internet searches, the French Supreme Court found that where automated word associations orient users towards keywords that may induce copyright infringement or other illicit behaviour the search engine may be found liable. The case was brought before the Supreme Court from the French phonographic industry lobby (SNEP) that started proceedings against Google for providing the suggestions 'Megaupload', 'Rapidshare' and 'Torrent' alongside names of performers and titles of songs. Both the Court of First Instance and the Court of Appeal had found that such automated word associations do not make Google responsible for activities performed by Internet users, and did not uphold SNEP's claims for piracy censorship in autocomplete suggestions. Overturning the decisions of the lower courts, the Supreme Court found that Google's autocomplete feature actually 'systematically orients internet users' towards illegal websites, so that the 
suppression of the suggestions at stake would make the search more difficult. To turn back to our earlier discussion, the algorithmically generated suggestions were not mere predictions but had the potential of directing users to particular searches and the capacity of even inducing illicit behaviour. While not totally effective, the measures requested by SNEP to order the removal of these words from the autocomplete feature were found capable of 'preventing or terminating such infringements', 'without compromising the efficiency' of the search engine. ${ }^{141}$

On other instances, word associations may not only induce infringing behaviours, but may represent themselves an infringing use of an intellectual property right. The matter was discussed in a UK case on unauthorized use of a trade mark in online retailing: the owner of the mark 'LUSH', registered for cosmetics and toiletries, complained that Amazon was using the mark to direct consumers to competing products. ${ }^{142}$ One of the allegedly infringing uses related to the fact that when a consumer started typing the search term 'lush' in the search bar of Amazon, a drop-down menu appeared suggesting various products that where similar or equivalent-in a word: competitive- to those sold by the claimant. ${ }^{143}$ To the Judge, this is a use of the claimant's sign in the course of trade which affected the function of the trade mark and was capable of confusing the average consumer. ${ }^{144}$

In these two cases, search suggestions were not considered to be meaningful linguistic units as in the cases involving personality rights. The intellectual property cases instruct that, even when the value of word associations rests in their instrumental role as search facilitators, they may have legal significance 'precisely because' they facilitate retrieving information that would otherwise remain obscure, or that may confuse consumers. In this way, the 'mere facilitation' argument by which courts discharge search engines for autocomplete suggestions returns by the back door to fix them with liability for copyright or trade mark infringement.

\section{CONCLUSION: THE APPROPRIATE SCOPE OF SEARCH ENGINE LIAB ILITY}

This article was concerned with the liability of search engines for algorithmically generated search suggestions that may have an offensive or defamatory meaning, or may even induce infringement of intellectual property rights. Although censoring search results can be dangerous, there are instances where rights of individuals may be violated by the algorithm. Search engine liability in the context of automatically generated associations brings forward questions over conflicts of rights. On one side, there are

141 ibid.

142 Cosmetic Warriors Ltd v Amazon.co.uk Ltd [2014] EWHC 181 (Ch).

143 ibid, ss 11-13.

144 Quoting the Google France test (Case C-236/08 [2010] RPC 19), Baldwin QC concluded:

In circumstances where there is no overt indication whatsoever that Lush products are not available for purchase on the Amazon site and where the consumer has been informed (from the drop down menu) that Lush Bath Bombs are available, I do not consider that the average consumer would ascertain without difficulty that the goods to which he was directed did not originate from Lush.

ibid, s 66 . 
arguments in favour of the protection of the fundamental freedoms of speech and access to information, including overreaching principles such as net neutrality or Internet governance. On the other side, personality rights of individuals on the Internet ought to be preserved, especially when personal data are processed in a way that is disproportionate to the legitimate aim of facilitating the search of information online.

We have seen that arguments over the neutrality of algorithms may not offer a viable defence in all jurisdictions. In the USA, courts tend to uphold claims that the automatically produced suggestions are constitutionally protected speech. The validity of this defence is less likely in Europe, however, where freedom of expression does not commonly cover information imparted by automated applications such as algorithms. Search engines may be found liable for automatically generated suggestions when these impact on the personality interests of individuals. This is when the search engines legally qualify as publishers of the autocompleted suggestions. Under common law, this is likely the case when search engines have an intention to publish the content and know or should reasonably be aware of the offensive content upon notification.

Once allegations for defamation or breach of data protection laws arise, search engines may avoid liability if one of the e-commerce defences for Internet service providers applies. We have seen that the application of these defences, such as caching and hosting, has not reached a level of harmonization across the EU and at the same time these defences tend to be variably applied to different torts, especially in the context of the autocomplete function. This means that in spite of the availability of the defences, different outcomes may be reached depending on the tort that has allegedly taken place, ie defamation, copyright infringement or data protection breaches.

With regards to defamation by the algorithm, European courts have sporadically developed a judicial trend upon which liability is more likely to be established when there are reasonable user's expectations that the autocompleted suggestion relates to content that is indexed by the search engine and hence hold some informative value. The focus in this discussion is not on the source of the content, ie the algorithm, but on its recipients, who can have a viable claim once false suggestions appear to reflect content-related associations. This was, for instance, the case in the decision of the German Supreme Court, where a search engine was ordered to remove such false suggestions upon receipt of notification from Internet users. In other cases, however, search engines have escaped liability. This was the case where arguments over the neutrality of the algorithm, that merely serves a functional purpose, were upheld. Arguments in favour of freedom of information have also been successful in some occasions, ie instances where the algorithm was found to merely facilitate the search.

The so-called facilitation argument was also raised in instances involving allegations for inducement of infringement of intellectual property rights, although in these cases a different outcome was reached. In this context, liability was established where automated word associations oriented users towards keywords that could be found as inducing copyright infringement or other illicit behaviour. It should be borne in mind, however, that lobbying against intellectual property infringement was powerful enough as to lead to the ab initio removal of specific keywords, such as the word 
'torrent', through policy filters that were mutually agreed between search engines and the intellectual property industries.

When automated suggestions contain personal information, however, complaints have to be brought by the specific individuals that have been affected, either on grounds of defamation or possibly on the basis of data protection law. The case of algorithmically produced suggestions is certainly more straightforward in the aftermath of the Google Spain case, according to which the processing of data that are no longer relevant goes against the provisions of EU Law. Although this case dealt with the obligation to remove search results upon notification, it gives a clear prevalence to arguments favouring a right to informational self-determination that could also apply to automatically produced suggestions. With the recently introduced obligations of Internet service providers to remove content upon user requests it is likely that search engines will soon be under a generalized obligation to erase search suggestions, irrespective of whether they are offensive, prejudicial or defamatory, although such a specific request is not specifically listed in the notice and take down forms that are currently available online. As applied to the autocomplete function, the doctrinal insight developed in Google Spain is more akin to a right to organize the information about oneself, in the form of a right of informational self-determination that seems to include but not limit itself to the right to be forgotten. 